\title{
Biofeedback Effect of Thoracic Excursion in Chest Expansion Training*
}

\author{
Takeshi ANDO**,***, Kazuya KAWAMURA***, Junko FUJITANI****, \\ Tomokazu KOIKE****, Yukiko NISHIGAKI****, Hiroko MIZUGUCHI****, \\ Masashi FUJIMOTO**** and Masakatsu G. FUJIE*** \\ ** Graduated School of Medicine, Osaka University, 1-7, Yamadaoka, Suita, Osaka, 565-0781, Japan \\ E-mail: takecando@gmail.com \\ ${ }^{* * *}$ Faculty of Science and Engineering, Waseda University, \\ 3-4-1, Ohkubo, Shinjyuku, Tokyo, 169-8555, Japan \\ **** Department of Rehabilitation, National Center of Global Health and Medicine \\ 1-21-1, Toyoma, Shinjyuku, Tokyo, 162-8655, Japan
}

\begin{abstract}
Improvement of thoracic mobility is important for patients with diseases such as chronic obstructive pulmonary disease (COPD). Chest expansion training is often conducted to increase the thoracic excursion. However, it is difficult for the patients to keep the motivation for rehabilitation, because the chest excursion is only measured. In this paper, we analyze the effect of real-time biofeedback on thoracic excursion. In 30 healthy subjects, thoracic excursion was increased by $6 \mathrm{~mm}(17 \%)$ when using the biofeedback system. Our results confirmed that we have developed an effective system for rehabilitation of respiratory function.
\end{abstract}

Key words: Rehabilitation, Biomedical Measurement, Respiration, Biofeedback

\section{Introduction}

The ability to accurately evaluate respiratory function is important in disorders such as chronic obstructive pulmonary disease (COPD), ankylosing spondylitis, asthma, thoracic scoliosis and cystic fibrosis, where respiratory dysfunction can be dangerous and even fatal $(1-5,10)$. Some pulmonary rehabilitation programs and certain medications can affect respiration, and monitoring of these effects can be useful to the clinical researcher ${ }^{(6)}$. It is also important to evaluate respiratory function before and after surgery.

Thoracic excursion, which is defined as the difference in chest circumference between maximal exhalation and maximal inhalation ${ }^{(11)}$, is one of the simplest and most important indexes used to evaluate respiratory function. Thoracic excursion therapy is undertaken to improve thoracic mobility and flexibility, as a decrease in thoracic excursion also decreases amount of ventilation in every breath and leads to exacerbation of fatigue and shortness of breath.

In clinical rehabilitation, thoracic excursion is measured manually by measuring chest expansion using a tape measure ${ }^{(7,10)}$. This method is very simple for the physical therapist. Some researchers have developed chest circumference measurement devices. Verzar developed a thoracometer ${ }^{(12)}$. Wade used a mercury-in-rubber strain gage system to measure movement of the thoracic cage ${ }^{(13)}$. Tawa et al used optical and acceleration sensors ${ }^{(8)}$. Merritt et al developed a textile-based sensor to monitor respiration ${ }^{(9)}$. These measurement systems have been well evaluated, but patients have difficulty understanding their respiratory function and sustaining motivation for rehabilitation using either a

*Received 7 Nov., 2011 (No. 11-0680) [DOI: 10.1299/jbse.7.328]

Copyright $(\odot 2012$ by JSME 
conventional tape measure or the other previously developed methods, because thoracic excursion is only measured.

Biofeedback is a technique that trains people to improve their health or body by controlling certain bodily processes that are normally involuntary, such as heart rate, blood pressure, muscle tension and skin temperature. Sensors measure these parameters and electronically convert the information to auditory, visual or tactile information. Such biofeedback systems are very effective in rehabilitation ${ }^{(14,15)}$. However, no biofeedback system has been developed for respiration, and the effects of such a system for respiration have not been evaluated.

The purpose of this study was to analyze the effect of real-time visual biofeedback of measured thoracic excursion on respiration. As a first step, the developed system was evaluated using healthy subjects.

\section{Methods}

\subsection{Instrumentation}

A wire type linear encoder (Microtech Laboratory Inc., MLS-30, resolution: $0.2 \mathrm{~mm}$, multiplication: 4) was selected as a sensor to measure changes in chest circumference (Fig. 1). The wire was wrapped around the chest at the level of the axillae and xiphisternum (Fig. 2). Chest circumference was measured using a counter board (USB connection, CONTEC, CNT24-2(USB)GY, sampling time: $50 \mathrm{msec}$ ). Thoracic excursion, di, was calculated as follows:

$$
d_{i}=M A X_{i}-M I N_{i}
$$

where $d_{i}$ is the thoracic excursion for $i$ number of breaths, $M A X_{i}$ is the maximum chest circumference in $i$ number of maximal inhalations and $M I N_{i}$ is the minimum chest circumference in $i$ number of maximal exhalations.

Figure 3 shows an example of the presentation of the graphical user interface $(\mathrm{C}++$ Builder) for the patient and physical therapist. Time-series data of chest circumference, current chest circumference, thoracic excursion in the last breath $(d$-max) and average thoracic excursion ( $d$-ave) are shown.

The interface screen is designed simply and intuitively. The physical therapist only has to enter the patient's name and click three times to measure thoracic excursion and print out the data. The setup time to start measuring thoracic excursion is less than 1 minute.

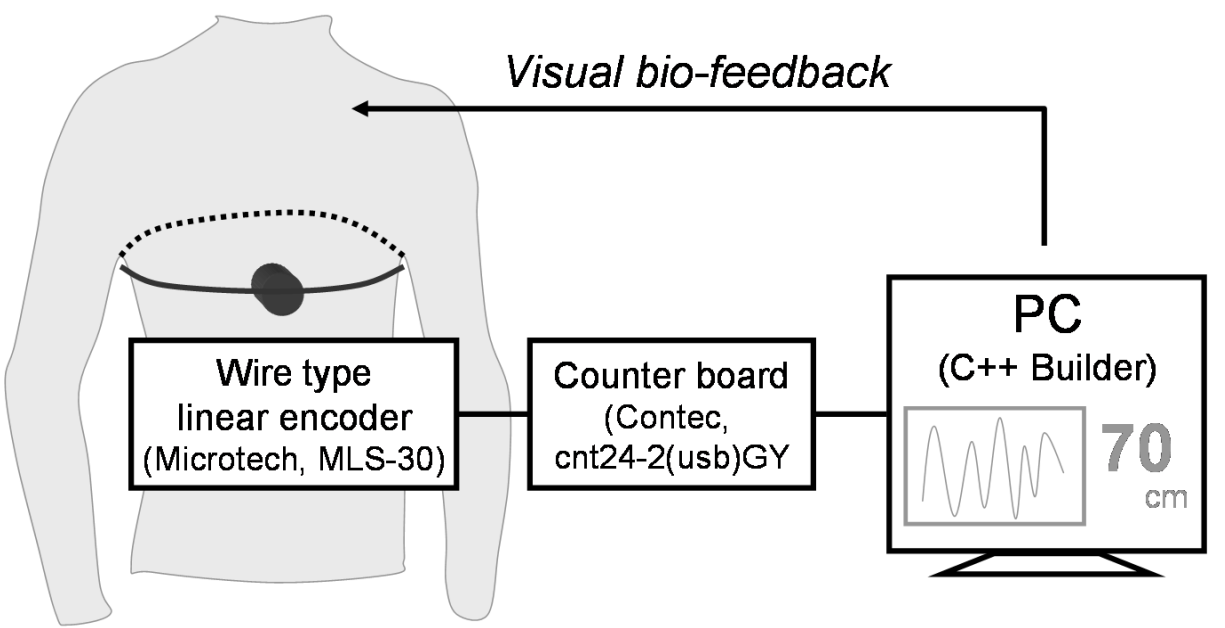

Fig. 1 Components of the automated thoracic excursion measurement and biofeedback system 


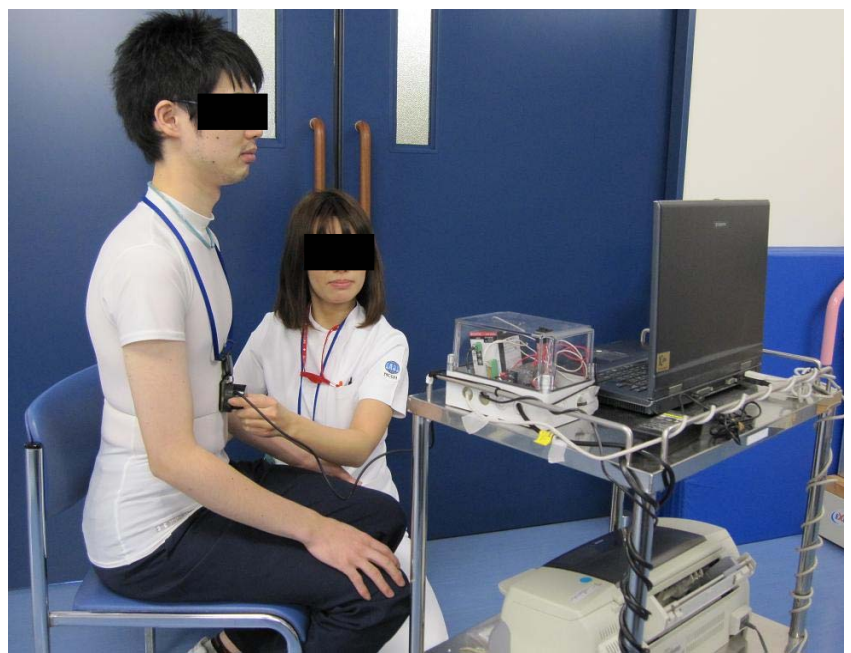

Fig. 2 Chest circumference measurement system

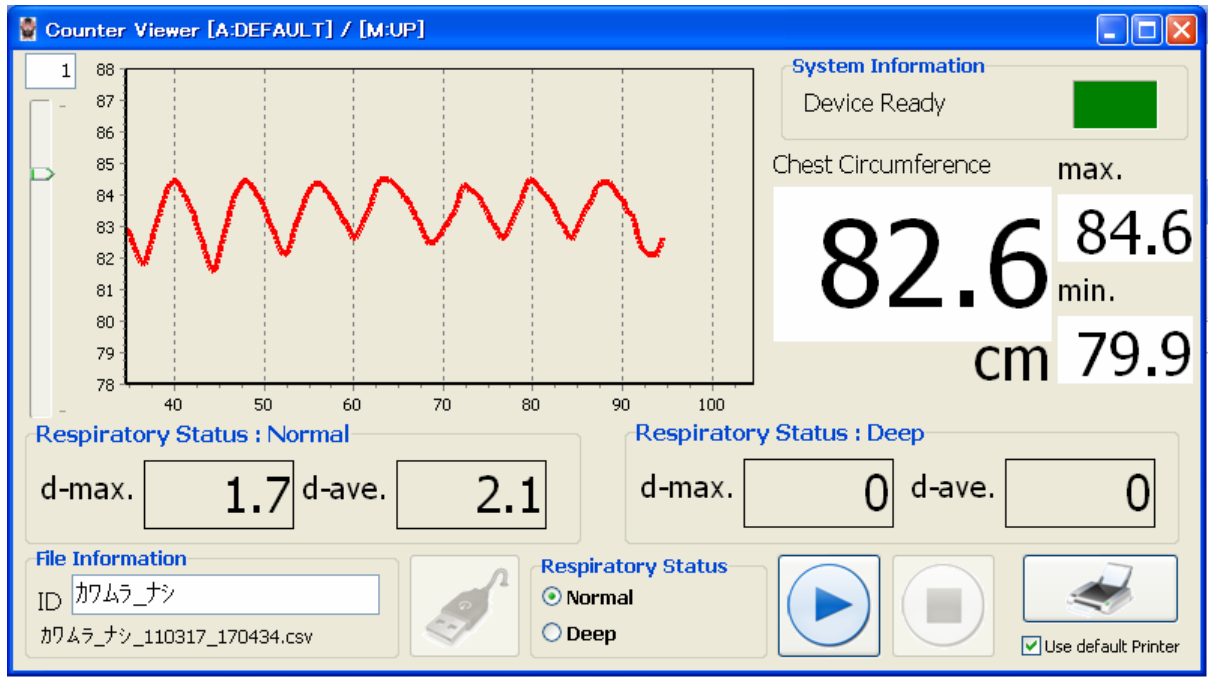

Fig. 3 Visual biofeedback system

\subsection{Experimental protocol}

Thirty healthy young subjects (age: $24.5 \pm 2.4$ years, height: $1.66 \pm 0.08(\mathrm{~m})$, weight: $56.5 \pm 8.3(\mathrm{~kg})$, body mass index (BMI): $20.3 \pm 2.1(\mathrm{~kg} / \mathrm{m} 2))$ wore the measurement device at the level of the xiphisternum ${ }^{(21)}$. Vital capacity, which is one of the most important indexes in respiratory function, is strongly correlated with thoracic excursion at this level. The subjects wore the thin shirt to reduce the influence of the subject's clothes.

All subjects were initially instructed to take ten breaths as deeply as possible. Before the experiment, the subjects were told "Take breaths as deeply as possible to exceed last chest excursion." The subjects were then randomly divided into two groups: Group A (15 subjects, age: $24.8 \pm 2.4$ years, height: $1.64 \pm 0.09(\mathrm{~m})$, weight: $52.9 \pm 6.7(\mathrm{~kg})$, BMI: 19.7 $\pm 1.8(\mathrm{~kg} / \mathrm{m} 2))$ and Group B (15 subjects, age: $24.1 \pm 2.4$ years, height: $1.69 \pm 0.06(\mathrm{~m})$, weight: $60.1 \pm 8.4(\mathrm{~kg})$, BMI: $20.9 \pm 2.2(\mathrm{~kg} / \mathrm{m} 2))$. The subjects in Group A were instructed to take ten deep breathes while watching the biofeedback screen, followed by ten deep breaths without watching the screen. The subjects in Group B were instructed to take ten deep breaths without watching the biofeedback screen, followed by ten deep breaths while watching the screen. Subjects were given adequate time to rest between these deep breaths. Before the test, the subjects understood the meanings of all graph and values in biofeedback screen. They found how to change screen by conducting their breath about five times. Each subject selected information which was easy to improve or maintain his or her chest 
excursion.

This study was approved by the institutional review board at Waseda University, Tokyo, Japan (\#2011-009). Consent was obtained from all study participants, and they were informed that they could withdraw at any time if they wanted to. Subjects practiced taking deep breaths before the onset of the experiment, and screen presentation of the real-time biofeedback system was explained to them.

\subsection{Statistic}

Unpaired t-test with two-tailed test was used to show the effectiveness of the biofeedback system. All statistical analyses were performed using SPSS statistical software (Version 18.0J, SPSS Japan Inc., Tokyo, Japan).

\section{Result}

Figure 4 shows the thoracic excursion data of all subjects. Thoracic excursion when biofeedback was used $\left(d_{w i t h}\right)$ was $53 \pm 22(\mathrm{~mm})$, and when biofeedback was not used $\left(d_{w / o}\right)$ was $46 \pm 21 \mathrm{~mm}$. Thoracic excursion was $6 \pm 4(\mathrm{~mm})$ more with biofeedback than without, which is a statistically significant difference (paired t-test, $\mathrm{t}=5.12, d f=29, p<0.00001$ ).

Comparison of physical characteristics between Group A and Group B found a significant difference only in weight (unpaired t-test, $\mathrm{t}=-2.56, d f=28, \mathrm{p}<0.05$ ) (Table 1).

Thoracic excursion data for Group A and Group B is summarized in Table 1. As shown in Fig. 5, thoracic excursion was greater with biofeedback than without in both Group A (paired t-test, $\mathrm{t}=3.36, d f=14, \mathrm{p}<0.01$ ) and Group B (paired $\mathrm{t}$-test, $\mathrm{t}=4.23, d f=14, \mathrm{p}<$ $0.001)$. The percentage change in thoracic excursion resulting from biofeedback was compared between Group A and Group B. The biofeedback effect, $R_{B F}$, defined as the percentage change in thoracic excursion with biofeedback versus without biofeedback, was normalized against thoracic excursion without biofeedback:

$$
R_{B F}=\frac{d_{\text {with }}-d_{w / o}}{d_{w / o}} \times 100
$$

The $R_{B F}$ of Group A was $11 \pm 11 \%$ and that of Group B was $22 \pm 19 \%$, which is a statistically significant difference (unpaired $\mathrm{t}$-test, $\mathrm{t}=-2.14, d f=28, \mathrm{p}<0.05$ ).

Table 1. Patient characteristics and thoracic excursion data

\begin{tabular}{|c|c|c|c|}
\hline & $\begin{array}{c}\text { Total } \\
(N=30)\end{array}$ & $\begin{array}{c}\text { Group A } \\
(N=15)\end{array}$ & $\begin{array}{c}\text { Group B } \\
(N=15)\end{array}$ \\
\hline Age (years) & $24.5 \pm 2.4$ & $24.8 \pm 2.4$ & $24.1 \pm 2.4$ \\
\hline Height $(\mathrm{m})$ & $1.66 \pm 0.08$ & $1.64 \pm 0.09$ & $1.69 \pm 0.06$ \\
\hline Weight $(\mathrm{kg})^{*}$ & $56.5 \pm 8.3$ & $52.9 \pm 6.7$ & $60.1 \pm 8.4$ \\
\hline BMI (kg/m $\left.{ }^{2}\right)$ & $20.3 \pm 2.1$ & $19.7 \pm 1.8$ & $20.9 \pm 2.2$ \\
\hline $\begin{array}{c}\text { Thoracic excursion without BF, } \\
d_{\text {w/o }}(\mathrm{mm})\end{array}$ & $46 \pm 21$ & $46 \pm 20$ & $47 \pm 23$ \\
\hline $\begin{array}{c}\text { Thoracic excursion with BF, } \\
d_{\text {with }}(\mathrm{mm})\end{array}$ & $53 \pm 22$ & $50 \pm 19$ & $55 \pm 24$ \\
\hline BF effect, $d_{\text {with }}-d_{w / o}(\mathrm{~mm}) *$ & $6 \pm 4$ & $4 \pm 4$ & $9 \pm 8$ \\
\hline BF effect, $R_{B F}(\%)^{*}$ & $17 \pm 11$ & $11 \pm 11$ & $22 \pm 19$ \\
\hline
\end{tabular}

* indicates a significant difference between Group A and Group B (unpaired t-test, p < 0.05). BF: biofeedback. All values shown as mean \pm standard deviation. 


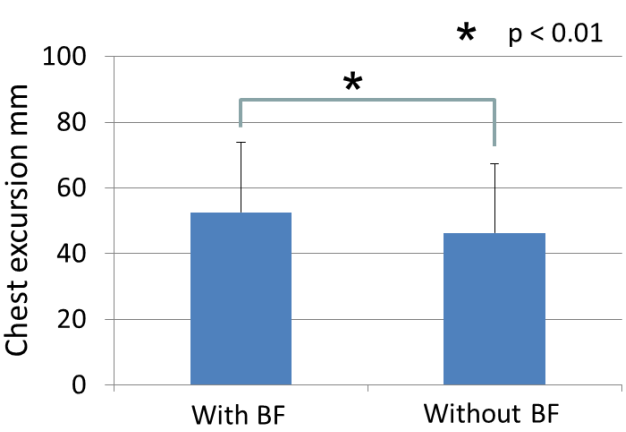

Fig. 4 Thoracic excursion measurements with and without the biofeedback system. Note that error bars show the standard deviation.

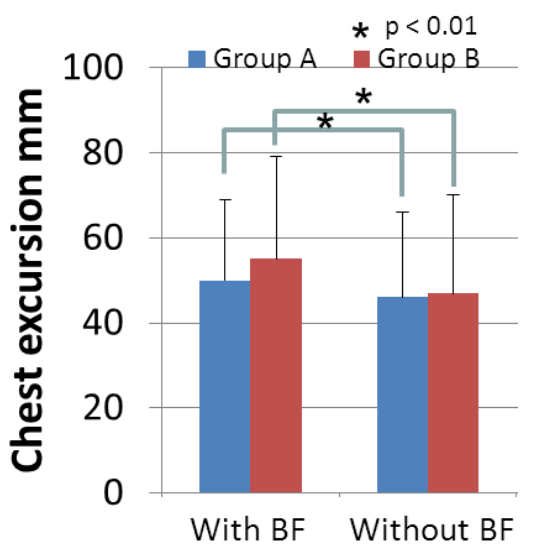

Fig. 5 Difference between thoracic excursion measurements with and that without the biofeedback system. Note that error bars show the standard deviation.

\section{Discussion}

There are a many studies evaluating respiration, as it is one of the most important bodily functions. Most studies focus on aspects such as vital capacity and $\mathrm{SpO}_{2}$. However, there are few studies evaluating thoracic excursion, even though measurement of chest expansion is one of the most frequently used methods to undertake and evaluate pulmonary rehabilitation. Jennifer et al ${ }^{(16)}$ measured thoracic excursion in healthy young people, and reported thoracic excursion of $51 \pm 62(\mathrm{~mm})$. Thoracic excursion measured in this study was $46 \pm 20 \mathrm{~mm}$ without biofeedback and $53 \pm 22(\mathrm{~mm})$ with biofeedback, which is very similar to the figures reported in Jennifer's study.

Biofeedback increased thoracic excursion by $6 \pm 4(\mathrm{~mm})\left(R_{B F}=17 \pm 11 \%\right)$ in this study, showing biofeedback to be effective in chest expansion training. As shown on the Konno-Mead Diagram ${ }^{(17)}$, thoracic excursion is an indicator of ventilation. Our results therefore indicate that biofeedback increases ventilation. Based on Tabata's equation (18) which shows the relationship between thoracic excursion and vital capacity in Japanese persons, biofeedback increases vital capacity by $71 \pm 47(\mathrm{~mL})$. According to Wither's prediction ${ }^{(19)}$ which shows a high correlation between vital capacity and thoracic excursion, vital capacity is increased by an average of $354(\mathrm{~mL})$ through using biofeedback of thoracic excursion.

The effect of biofeedback on thoracic excursion was larger in Group B (the subjects who did not use biofeedback for the first breath) than in Group A (the subjects who used biofeedback for the first breath). There are two possible reasons for this difference. First, the subjects in Group A may have regarded the data presented by the biofeedback as their best possible thoracic excursion because it was their first attempt, and they did not have a previous deep breath to compare with. Second, thoracic mobilization may have been immediately improved by the use of biofeedback ${ }^{(20)}$. However, our data shows that thoracic excursion without biofeedback was almost the same in Group A as in Group B (Table 1), so the first reason seems more likely.

\section{Conclusion}

Thoracic excursion is one of the simplest and most useful indexes used to evaluate respiratory function. In this paper, we analyzed the effect of the biofeedback system on respiratory function. Our results showed that it was easier to maintain a large thoracic 
excursion during deep breathing when using a real-time visual biofeedback system showing chest expansion.

Currently, three chest excursion biofeedback systems are used in the clinical rehabilitation. Reliability and repeatability of developed system will be reported by collaborated therapists in National Center of Global Health and Medicine. According to the medical doctor and physical therapists comments, the developed system is qualitatively effective to improve the motivation of the respiration rehabilitation. We plan to undertake further studies to measure long-lasting effects of this biofeedback method on respiratory rehabilitation, including use in patients with conditions such as COPD.

\section{Acknowledgment}

We sincerely thank the all subjects who took part in this study. This work was supported in part by the MEXT Global Center of Excellence Program "Global Robot Academia", Waseda University, Tokyo, Japan and the MEXT Grant-in-Aid for Scientific Research (22700582).

\section{References}

(1) PH Bennett and TA Burch, "New York symposium on population studies in the rheumatic diseases: new diagnostic criteria," Bull Rheum Dis., vol.17, pp 453-458, 1967.

(2) Bennett PH, Burch TA. The epidemiological diagnosis of ankylosing spondylitis (AS). In: Bennett PH, Wood PHN, eds. Population Studies of the Rheumatic Diseases. Amsterdam, Netherlands: Excerpta Medica; 1968:305-313.

(3) Hartung EF. Arthritis. In: Bett WR, ed. The History and Conquest of Common Diseases. Norman, Okla: University of Oklahoma Press; 1954:133.

(4) Hawes MC, Brooks WJ. Improved chest expansion in idiopathic scoliosis after intensive, multiple-modality, nonsurgical treatment in an adult. Chest. 2001;120:672-674. Available at (Accessed March 29, 2011): http://www.chestjournal.org/cgi/content/full/120/2/672. .

(5) Leong JC, Lu WW, Luk KD, Karlberg EM. Kinematics of the chest cage and spine during breathing in healthy individuals and in patients with adolescent idiopathic scoliosis. Spine. 1999;24:1310-1315.

(6) Linden, S. V. D., Valkenburg, H. A. and Cats, A., Evaluation of Diagnostic Criteria for Ankylosing Spondylitis. Arthritis \& Rheumatism, 27, 1984, pp. 361-368.

(7) Susan E. Bockenhauer, Haifan Chen, Kell N. Julliard, Jeremy Weedon, Measuring Thoracic Excursion: Reliability of the Cloth Tape Measure Technique, J Am Osteopath Assoc 2007, 107, 191-196

(8) Tawa, H.; Yonezawa, Y.; Maki, H.; Ogawa, H.; Ninomiya, I.; Sada, K.; Hamada, S.; Caldwell, W.M.; A wireless breathing-training support system for kinesitherapy, Annual International Conference of the IEEE EMBC 2009, 5179 - 5182, 2009

(9) Merritt, C.R.; Nagle, H.T.; Grant, E.; Textile-Based Capacitive Sensors for Respiration Monitoring, IEEE Sensors Journal,, 9(1), 2009, 71 - 78

(10) Custers JW, Arets HG, Engelbert RH, Kooijmans FT, van der Ent CK, Helders PJ., thoracic excursion measurement in children with cystic fibrosis, J Cyst Fibros, 2005, May; 4(2), 129-133

(11) Carlson B., Normal chest excursion, Phys Ther., 1973 Jan, 53(1), 10-14

(12) Verzar, 1946F. Verzar, The regulation of lung volume and its disturbance, Schweiz. Med. Wochenschr. 76 (1946), pp. 932-936

(13) OL Wade, Movements of the thoracic cage and diaphragm in respiration, The Journal of Physiology, 1954, 124, 193-212

(14) Riener, R. et al, Patient-cooperative strategies for robot-aided treadmill training: first 
experimental results, IEEE Transactions on Neural Systems and Rehabilitation Engineering, 13(3), 2005, 380 - 394

(15) Sanchez, R.J et al, Automating Arm Movement Training Following Severe Stroke: Functional Exercises With Quantitative Feedback in a Gravity-Reduced Environment, IEEE Transactions on Neural Systems and Rehabilitation Engineering, 14(3), 2006, 378 389

(16) LaPier, T.K, Debra Stewart et al, Chest wall expansion values in supine and standing across the adult lifespan, Physical and Occupational Therapy in Geriatrics, 21(1), 65-81, 2002

(17) Konno K, Mead J., Measurement of the separate volume changes of rib cage and abdomen during breathing, J Appl Physiol. 1967 Mar;22(3):407-22.

(18) Kazuyuki Tabata, Ryo Kozu, The Study on Equation for Predicting Pulmonary Function Using Chesst Expansion Scores in Middle and Old Aged Persons, Japanese physical therapy, 23(2), 66-71, 1996

(19) Withers RT, Bourdon PC, Crockett A.,Lung volume standards for healthy male lifetime nonsmokers, Chest. 1988; 93(1), 91-97.

(20) K. Tabira, N. Sekikawa, M. Iwashiro et al., The immediate effect of chest mobilization technique in patients with chronic obstructive pulmonary disease, Japanese physical therapy, 34(2), 59-64, 2007

(21) Mizuguchi et al, Reliability and Validity of a Biofeedback System that Measures Thoracic Extension, Respiration, (submitted), 2012 